\title{
Bilateral Reduction Mammoplasty
}

National Cancer Institute

\section{Source}

National Cancer Institute. Bilateral Reduction Mammoplasty. NCI Thesaurus. Code C51935.

Surgery to reduce the size of both breasts. 